\title{
Comparing problem based learning with lecture based learning on medicine giving skill to newborn in nursing students
}

\author{
Susan Penjvini, Sirioos Shahsawari \\ Pediatric Nursing Department, Faculty of Nursing and Midwifery, Kurdistan University of Medical Sciences, Iran \\ Correspondence: Susan Penjvini. Address: No 10, Ordibehesht alley, Sadi (Adab) street, Sanandaj, Kurdistan, Iran. \\ Telephone: 00988716622266. Email: susan.penjvini@muk.ac.ir.
}

Received: November 14, 2012

Accepted: January 18, $2013 \quad$ Online Published: February 27, 2013

DOI : 10.5430/jnep.v3n9p53

URL: http://dx.doi.org/10.5430/jnep.v3n9p53

\section{Abstract}

Purpose: Compare the effects of problem-based learning (PBL) method with traditional lecture in the skill of giving medicine to newborns in nursing students.

Background: PBL has attained a high educational level, because PBL is now generally believed to be an effective educational method, which can have a profound effect on enhancing students competency in practical and theoretical skills.

Methods: In this quasi experimental study, 29 fourth and fifth semester female students who were passing training in the neonatal ward were selected randomly in to PBL $(n=14)$ and LBL group $(n=15)$ and trained regarding the skill of giving medicine to newborns. Data were collected using two checklists for cognitive and psychomotor skills and two questionnaires regarding the students' viewpoints about self-assessment and self-improvement also students' satisfaction.

Results: The level of knowledge in the PBL group was significantly higher than that of students in the lecture group ( $p$ $<0.001)$. There was a significant difference between the students' cognitive and psychomotor skills scores in the lecture based learning group before and after learning ( $p=0.000, p=0.001$, respectively). However for the PBL group there was only a significant difference between performance before and after learning $(p=0.002)$. Also, there was a significant difference between cognitive learning scores before learning as well as a significant difference between post learning performance scores in the two groups $(p=0.008)$. We found a significant difference in the post learning phase between students' viewpoints $(P<0.001)$ and a significant difference between students' satisfaction in the pre- and post-learning phase in the PBL group (0.002).

Conclusion: Students in the PBL group gained more knowledge and had higher motivation toward learning compared to students in the lecture group. Therefore it is suggested that with more deep studies, changes of using the method of teaching upon PBL instead of common method, could be re considered.

\section{Key words}

Skill of giving medicine, Problem based learning (PBL), Lecture based learning (LBL) and students 


\section{I ntroduction}

Problem based learning (PBL), as a method of learning, has attained a high educational level. The first educational experiences of PBL was first developed by Howard Barrows at McMaster University in Canada in the mid 1960's ${ }^{[1]}$. This method is student-centered method can increase team working and students' communicating skills ${ }^{[2]}$ and self evaluation, peer evaluation skills, critical thinking and relationship skills ${ }^{[3]}$.

PBL aims to solve a problem in the learning process. The PBL method enables learners to solve a problem through a scientific and clinical scenario. The scenario approach is a stimulus for learners to gain necessary information about that problem and present new strategies to solve it ${ }^{[2]}$. Based on William, and Beattie problem based learning is an effective teaching strategy for nursing educators ${ }^{[4]}$. The rationale for using PBL is that the students should actively participate in the learning process and the presentation of information ${ }^{[5]}$.

According to Ladouceur et al. along with self-directed learning, the development of critical thinking and problem solving skills is the main goals of PBL ${ }^{[6]}$. Most studies stated PBL is a method which can connect theoretical learning and real clinical problems ${ }^{[4,7,8]}$. Moreover, this method familiarizes students with the world of real experiences and improves their vocational skills ${ }^{[9]}$.

Creedy and colleagues introduced the process of PBL as follows: First of all the scenario or learning situation is presented to students without prior study of the problem, of course design of the scenario was similar to real life situations. Then the student, as a member of a small group, works with the scenario until the results are obtained through systemic strategies of problem solving. While working with the scenario, the student identifies her learning domains. These domains are regarded as the guidance for the individual's studies. The achieved skills and knowledge through the identification of learning domains can be used as instruments for the effective evaluation of learning. The learning which is evolved by working with the scenarios is summarized and is integrated and harmonized with the current perception and knowledge of the student ${ }^{[10]}$.

Most PBL studies on nursing students showed that this method is a student centered method, which is adaptable to the clinical environment and its modifications ${ }^{[2,5,11,12]}$. Nursing experts believe that PBL, compared with traditional lecture based methods, is more effective ${ }^{[13,14]}$. Furthermore Aari, et al (2007) stated that (pbl - learning skills can carrying out toturials in nursing students' clinical practice ${ }^{[13]}$. In another study in Sweden, PBL strategy was conducted in clinical supervision of nursing students by Staun M, et al 2010, the results showed that most students were highly satisfactory and feel their times in clinical education had been used efficiently.

In medical education a few studies have been conducted to assess the effect of PBL in recalling information after a long period of time ${ }^{[16,17]}$. Also, few studies investigated the students' information level in the PBL and traditional methods and the application of PBL in real clinical problems in nursing ${ }^{[18]}$. However, there were no any studies relating to application of PBL in clinical setting in Iran. Probably this study is the first of this one.

Hence, an experimental study that compares the impact on students' learning outcome of PBL versus the traditional lecture method in clinical setting is a real need. In this study we aimed to assess whether PBL can be used as a learning strategy instead of the clinical situations, at least for part of their duties such as giving medicine to newborns. We also wanted to see whether this method could be useful in motivating and satisfaction of students to do research and group activities?

\section{Methods}

\subsection{Design}

This was a quasi experimental study which was undertaken to compare PBL and Lecture based learning (LBL) in the skill of giving medicine to newborns. Training in Neonatal ward does not have any prerequisites; however, all nursing students 
should be familiar with hospital conditions and working in clinics. Students pass this training course. The routine duration of training in the Neonatal ward, Besat hospital in Sanandaj is 9 days (Over three weeks and in the first or last three days of the week, totally, 5 groups five students and 1 group four students= 29 sstudent). The research protocol was approved by the ethical committee at the Kurdistan University of Medical Sciences. Nursing students volunteered to take part in this research and were assured of anonymity.

\subsection{Sample}

The students were selected randomly into two groups. They were trained regarding the skill of giving medicine to newborns using the lecture method (speech, marker and white board) or the PBL method (clinical scenarios). The fourth and fifth semester students (second semester of 2006-2007) were trained using the traditional lecture based method (comparison group, $\mathrm{n}=15$ ) and the fourth and fifth semester students (first semester of 2007 -2008) were trained using the PBL method (intervention group, $\mathrm{n}=14$ ). All the students in the two groups passed the theoretical course of mother and newborn health and were homogeneous regarding age, sex, and educational semester. They participated in neonatal training courses in groups of five.

Since all the students should apply their knowledge about the correct method of medicine giving to newborns from the beginning of training, necessary training regarding the five fundamental nursing rules consisting of the correct method of giving medicine, checking medicine in three phases, use of injection instruments, calculating drug dosage, and their possible side effects was given to the students on the first day.

The comparison group received traditional lectures throughout the semester on the same content areas.

When the second day of training was finished, the two intervention and comparison groups were given a pre-test regarding their mental and psychomotor skills and also their satisfaction with the learning method. Then, when the educational course finished and approximately a month later, the post-test or the test for recalling mental and psychomotor skills and the test on assessing their perception toward their improvement was used.

Mental and psychomotor skills were taught to the students in the intervention group using the following: In the first place the problems by the trainer (researcher) presented to the students as scenarios and explanation of terminologies, then accurate identification and specification of the problems by the students, and giving different thoughts to students and taking notes of their learning needs in relation to the problems, afterwards data collected out of educational councils such as searching in nursing books and the internet, then retelling the information in the presence of other students and the trainer (researcher) and investigating all notes, summaries, ideas and viewpoints that had been found in previous studies and giving a copy of presented materials of each student to the trainer and other students.

In this study, the students in the intervention group understood the scenarios on the first three days of the week and used it in the Neonatal ward and then collected data and prepared their ideas and viewpoints on the second three days of the week. In the following week, before being given the next scenario, they gave a summary about their work procedure to the head of the group and other students.

\subsection{Data collection and Management}

Data collection tools that applied in this research as follows: the questionnaire of cognitive skills, which consisted of nine questions including three questions regarding the five regulations of correct method of giving medicines, three questions related to checking drugs, and three questions about the correct way of using necessary instruments upon drug prescription. The correct answers were given +1 points and incorrect answers were given zero points. Total scores ranged from zero to nine and the assessment was done by calculating the mean scores and standard deviations. This questionnaire was validated based on content validation and by use of nursing textbooks and the viewpoints of nursing experts. The checklist for psychomotor skills in which the trainer evaluated the students' behavior regarding giving medicine to 
newborns. For each medicine giving skill, the trainer selected one of the following choices: 1 . seldom, 2. sometimes, and 3. most of the time. The total scores ranged from 0-12 and assessment was done by evaluating mean scores and standard deviations. The satisfaction evaluation questionnaire (including 7 statements regarding satisfaction with the method and satisfaction with the effective learning) which was developed by Rideout, E. (1999) and used to assess the students' satisfaction level. In this questionnaire, the students could select one of the following four choices: not satisfied at all, somehow satisfied, satisfied, and very satisfied ${ }^{[17]}$.

Finally to evaluate the students' viewpoints regarding their self-evaluation at the end of the second phase (one mount after intervention) the participants in both groups stated their opinion about self-improvement in traditional or PBL leaning methods using an 8-item questionnaire. They could select one of the following four choices five each item: I highly agree, I agree, I have no opinion, I disagree, and I highly disagree. They were assessed for having positive or negative perceptions.

\subsection{Findings}

In the comparison group, the mean $( \pm \mathrm{SD})$ pre- and post-test scores of the student’s were $6.53( \pm 0.99)$ and $7.93( \pm 0.7)$, respectively, which showed a significant improvement in cognitive and psychomotor skills $(P<0.001)$. Regarding group's psychomotor skills, the mean $( \pm \mathrm{SD})$ scores were $6.40( \pm 1.72)$ and $8.33( \pm 0.89)$, respectively, and a significant difference was seen (see Table 1). In the intervention group, we found no significant difference between pre- and post-test results regarding the level of cognitive skills. As for psychomotor skills, the pre- and post-test scores of the student's were 7.42 $( \pm 1.55)$ and $9.35( \pm 1.008)$, respectively $(P=0.002$, table 1$)$. In the comparison between the mean pre- and post-test scores of cognitive skills between the two groups, we found that the mean $( \pm S D)$ pre-test scores were $6.53( \pm 0.99)$ and 8.14 $( \pm 0.66)$ in the comparison and intervention groups, respectively, which confirmed a significant difference. However post-test results showed no significant difference between the two groups. With respect to psychomotor skills the pre-test scores were $6.4 \pm 1.72$ and $7.42( \pm 1.55)$ in the comparison and intervention groups, respectively. The corresponding figures for the post-test scores were 8.33( \pm 0.89$)$. 9.35 ( \pm 1.008 ), respectively (see Table 2 ).

Table 1. Comparing the pre- and post-test results of the students' cognitive and psychomotor skills in the comparison and intervention groups

\begin{tabular}{|c|c|c|c|c|c|}
\hline \multirow{2}{*}{ Groups } & \multirow{2}{*}{ Learning phase } & \multicolumn{2}{|c|}{ Cognitive Skills } & \multicolumn{2}{|c|}{ Psychomotor Skills } \\
\hline & & $\operatorname{Mean}( \pm$ SD) & $P$ Value & Mean( \pm SD $)$ & $P$ Value \\
\hline \multirow{3}{*}{ Comparison $(n=15)$} & Pre-test & $6.53( \pm 0.99)$ & \multirow{3}{*}{$<0.001$} & $6.4( \pm 1.72)$ & \multirow{3}{*}{0.001} \\
\hline & & & & & \\
\hline & Post-test & $7.93( \pm 0.7)$ & & $8.33( \pm 0.89)$ & \\
\hline \multirow{2}{*}{$\begin{array}{l}\text { Intervention group } \\
(\mathrm{n}=14)\end{array}$} & Pre-test & $8.14( \pm 0.66)$ & \multirow{2}{*}{0.13} & $7.42( \pm 1.55)$ & \multirow{2}{*}{0.002} \\
\hline & Post-test & $8.50( \pm 0.51)$ & & $9.35( \pm 1.008)$ & \\
\hline
\end{tabular}

Table 2. Mean $( \pm S D)$ pre- and post-test scores of the students' cognitive (knowledge) and psychomotor skills (behavior) in the two groups

\begin{tabular}{lllll}
\hline Skills & Learning phase & Comparison group & Intervention group & $P$ Value \\
\hline \multirow{2}{*}{ Cognitive } & Pre-test & $6.53( \pm 0.099)$ & $8.14( \pm 0.66)$ & $<0.001$ \\
& Post-test & $7.93( \pm 0.70)$ & $8.5( \pm 0.51)$ & 0.21 \\
\multirow{2}{*}{ Psychomotor } & Pre-test & $6.4( \pm 1.72)$ & $7.42( \pm 1.55)$ & 0.104 \\
& Post-test & $8.33( \pm 0.89)$ & $9.35( \pm 1.008)$ & 0.008 \\
\hline
\end{tabular}

By comparing the mean (SD) post-test scores of the students in both groups, we found that the students had significantly positive attitudes and perceptions towards self-improvement during their educational course (27.92 ( \pm 3.04$)$ vs. 20.73 
$( \pm 4.66)$ in the intervention and comparison groups respectively, $P<0.001)$ (see Table 3 ). The mean pre- and post-test satisfaction scores in the intervention group were $6.57( \pm 2.17)$ and $9.71( \pm 1.20)(P=0.002)$ (see Table 4).

Table 3. Mean (SD) scores of the students' attitude in the two groups

\begin{tabular}{llll}
\hline Education stage & Comparison group $=\mathbf{1 5}$ & Intervention group=14 & P value \\
\hline After education & $20.73( \pm 4.66)$ & $27.92(3.04)$ & 0.000 \\
\hline
\end{tabular}

Table 4. Mean $( \pm \mathrm{SD})$ before and after education scores of the students’ satisfaction in PBL group

\begin{tabular}{lll}
\hline Education stage & Mean $( \pm$ SD) & $P$ value \\
\hline Before education & $6.57( \pm 2.17)$ & 0.002 \\
\hline
\end{tabular}

\section{Discussion}

Walsh stated that PBL is based on the slovenly, complex problems encountered in the real world as a stimulus for learning to use scientific knowledge for real problems ${ }^{[16]}$. We found that the students' cognitive skills in the comparison group improved in the post-learning phase and there was a significant difference between the mean post and pre-test scores. This finding is comparable with that of the Iranian study ${ }^{[14]}$ and Korean study ${ }^{[18]}$. However, in the intervention group we found no significant difference between the mean pre- and post-test scores. The reason might be that in the PBL method, the students are confronted with case studies, accurate observation, and self-learning for the first time. Our results are consistent with some other studies ${ }^{[13,14]}$.

Psychomotor skill results showed that in the intervention group these skills improved more than the lecture based group. In a study conducted by Szogedi et al. regarding the improvement of psychomotor skills in CPR exam gained the same results ${ }^{[19]}$. PBL experience in clinical setting can improved nursing students' interest in practice ${ }^{[8]}$ and can definitely change attitudes towards nursing care ${ }^{[20]}$. We found that the rate of satisfaction in the intervention group in the post-learning phase was more than the comparison group. The other studies had previously found similar results ${ }^{[14,17,21]}$.

Regarding the attitudes of the students in both groups about self-improvement, we found that the attitudes of the learners in the intervention group were more positive than that of the comparison group. Kolini et al. in a study on problem based and lecture based learning in biology courses of medical students, found that the perception of the students towards research activities in short-term periods of PBL learning and group work was positive. The effect of teaching methods on motivating the students to conduct individual studies has also been investigated in other studies and the results indicate that the availability of resources and facilities, ample guidance time to do case studies, and the desire and need to solve daily problems, were intervening factors in motivating the students for conducting nursing care ${ }^{[21]}$.

One of the basic factors for vocational improvement is research and discovery by means of existing resources. Nurses who have such skills in the clinical environment can receive, control, and analyze the patients' problems in the best possible way ${ }^{[13]}$. Encouraging nurses to conduct pervasive case studies is one of the methods of vocational improvement and perfection. Educational methods can also be effective in vocational development

\section{Recommendations}

We recommend applying this method to other skills in nursing care in clinics and identify the features, advantages of this method and specify its effectiveness. 


\section{Conclusions}

With respect to the above mentioned findings, since teaching by PBL method will augmentation of learning improvement and student's satisfaction, more largeness use of this method and even replacing it as a traditional method in nursing practice education are suggested at the Nursing and Midwifery faculties.

\section{Author contributions}

SP and SS were responsible for the study conception and design. SP performed the data collection. SS \& SP performed the data analysis. SP was responsible for the drafting of the manuscript. SP \& SS obtained funding.

\section{Conflicts of interests}

The authors declare that they have no conflicts of interests.

\section{Acknowledgement}

We are grateful to the nursing students who participated in this study, nurses who worked in Neonatal ward in Besat hospital and mothers and their infants. This research was supported by a research grant from Research Team affiliated to Kurdistan University of Medical Sciences in Iran.

\section{References}

[1] OLiffe J, Grad Dip Adult. Facilitation in PBL- Espoused Theory versus Theory in use. Reflections of a first time user. AEJNE 2000; 5 (2): 1-9.

[2] Dehkordi. A.H, Heydarnejad, M.S. The effects of problem based learning and lecturing on the development of Iranian nursing students’ critical thinking. Pakistan Journal of Medical Sciences. 2008; (24): 740-43.

[3] Rowan C, McCourt C, Beake S. Problem based learning in midwifery- the students' perspective. Nurse Education Today. 2008; 28(1): 93- 99. PMid:17499395 http://dx.doi.org/10.1016/j.nedt.2007.02.014

[4] Williams SM, Beattie HJ. Problem-based learning in the clinical setting - a systemic review. Nurse Education Today. 2008; (3): 146-154. PMid:17919784 http://dx.doi.org/10.1016/j.nedt.2007.03.007

[5] Memarian R. Learning upon problem based learning (PBL) in medical sciences education. Journal of Nursing and Midwifery of Tehran University. 2000; (10): 47- 54.

[6] Ladouceur M. G, Rideout E M, Black M E A, Crooks D L, O'Mara L M, Schmuck, M. Development of an instrument to assess student performance in small group tutorials. Journal of Nursing Education. 2004; (43): 447-45. PMid:17152304

[7] Mesek KL, Yamins S. Problem based learning for epistemological competence: The knowledge acquisition perspectives. Journal of Technical Education and Training. 2011; 3(1): 29- 36.

[8] Ehrenberg AC, Haggblom M. Problem Based Learning in clinical nursing education: Integrating theory and practice. Nurse Education Practice. 2007; (7): 67-74. PMid:17689426 http://dx.doi.org/10.1016/j.nepr.2006.04.005

[9] Niemer L, Pfendt K, Gers M. Problem based learning in nursing education: a process for scenario development. Nurse Educator. 2010; (35): 69-73. PMid:20173591 http://dx.doi.org/10.1097/NNE.0b013e3181ced891

[10] Creedy D, Horsfall J, Hand B. Problem based learning in nurse education an Australian view. Journal of Advanced Nursing. 1992; (17): 227-233.

[11] Herzig S., Linke RM, Marxen B, Borner U\& Antepohl W. Long- term follow up of factual knowledge after a single randomized problem-based learning course. BMC Medical Education. 2003; 3: 3. PMid:12675949 http://dx.doi.org/10.1186/1472-6920-3-3

[12] Yuan HB, Williams BA, Yin L, Liu M, Fang JB, Pang D. Nursing students' view on the effectiveness of PBL. Nurse Education Today. 2011; 31(6): 577-581. PMid:21036431 http://dx.doi.org/10.1016/j.nedt.2010.10.009

[13] A“a”ri R L, Elomaa L, Ylo“nen M, Saarikoski M. Problem-based learning in clinical practice: Employment and education as development partners. Nurse education in practice. 2008; (8): 420-427. http://dx.doi.org/10.1016/j.nepr.2007.10.005

[14] Sangestani, G. \& Khatiban, M. Comparison of problem-based learning and lecture-based learning in midwifery. Nurse Education Today. 2012; (59): 376-9.

[15] Staun M, Bergstrom I.A, Wadensten B. Evaluation of a problem based learning strategy in clinical supervision of nursing students: Patients centered training in students-dedicated treatment rooms. Nurse Education Today. 2010; (30): 631-637. PMid:20061069 http://dx.doi.org/10.1016/j.nedt.2009.12.013 
[16] Walsh K. Learning Styles: Do they really exit? Medical Education. 2008; (41): 618-620.

[17] Khaki A A, Tubbs R Sh, Zarrintan S, Jabbari Khamnei H, Mohammadali Mohajel S, Sadeghi H, Ahmadi M. The First Year Medical Students' Perception of and Satisfaction from Problem-based Learning Compared to Traditional Teaching in Gross Anatomy: Introducing Problem-based Anatomy into a Traditional Curriculum in Iran. International Journal of Health Sciences. 2007; 1(1): 113-118.

[18] kim SY, Hwang MJ. A comparison of problem-based learning and lecture based learning in an adult health nursing course. Nurse Education Today. 2006; (26): 315-321. PMid:16364510

[19] Szogedi I, Zrínyi M, Betlehem J, Újváriné AS, Tóth H. Training nurses for CPR: support for the problem-based approach. European Journal of Cardiovascular Nursing. 2010; (9): 50-56. PMid:19892601 http://dx.doi.org/10.1016/j.ejcnurse.2009.09.003

[20] Francis I A, Noorani N. Promoting problem based learning in nursing education: Malaysian experience. Nurse Education in Practice. 2005; (5): 302- 311.

[21] Kolini. N, Farshidfar F, Shams B Salehi M. Problem based learning or speech: The experience of a new method of teaching biology to the medical freshmen of Medical Sciences university of Isfahan. The Iranian journal of Education in Medical Sciences. 2004; (10): 57-61. 